\title{
Research on the Mode of China's Power Spot Market
}

\author{
Menghua Fan ${ }^{1 *}$, Su Yang ${ }^{1}$, and Zheng Zhao ${ }^{1}$ \\ ${ }^{1}$ State Grid Energy Research Institute Co., LTD (SGERI), No. 18 Binhe Road, Future Science Park, Beijing, 102209, China
}

\begin{abstract}
At present, the construction of China's power spot market is advancing steadily. This paper studies the characteristics and functions of the spot market, analyses the market environment and requirements, studies the key elements and designs the market mode for the spot market under the new situation, and puts forward suggestions for some key problems in the actual operation. This paper can provide reference for promoting the top-level design and operation of China's power spot market.
\end{abstract}

\section{Introduction}

Power spot market generally includes day-ahead, intraday and real-time markets. Spot market generally has the following three characteristics [1]:

(1) Unified trading platform: centralized trading is carried out through bidding, matching and other ways to implement centralized clearing;

(2) Physical delivery: physical delivery shall be carried out in strict accordance with the trading results within a short period of time without additional conditions;

(3) Real time price: the price mainly reflects the change of real-time supply and demand, with poor predictability, fast change, high volatility and high price risk.

Compared with other spot markets, the power spot market has certain particularity. Firstly, the implementation of trading results should be guaranteed through mechanism design, such as the need to ensure the balance of power supply by dispatch, and to address the system design of deviation assessment. Secondly, the coordination between the spot market and the medium and long-term transactions must be considered, because the medium and long-term transactions need physical delivery at a certain time, which will affect the transmission constraints and real-time balance of the spot market at that time.

The functions of the spot market can be summarized as follows:

The first is to provide price signal. Through shortterm power supply and demand matching, the value of power commodity can be revealed.

The second is to optimize resource allocation. According to the price signal, the quantity and range of power resources in the market are adjusted continuously to realize the optimal allocation.

The third is to promote the consumption of new energy. The spot market can fully adapt to the uncertainty characteristics of new energy power generation, and give full play to the advantages of low marginal cost of new energy, while encouraging conventional generating units to participate in peak regulation.

\section{Power spot market construction environment in China}

The construction and design of China's power spot market must fully consider the characteristics of China's national conditions, including economic and social development stage, basic economic system, administrative management system, energy allocation and power grid structure [2].

(1) Reverse distribution of energy supply and demand and strong demand for large-scale optimal allocation of resources.

(2) The economic and social development takes Province as the main body. Power supply and balance is mainly based on province and the power transmission and distribution tariff is also regulated by province.

(3) Goverment planned and market based mechanism will coexist for a long time, and market construction needs to achieve a smooth transition.

(4) With the rapid growth of new energy installation, the task of promoting energy low-carbon transformation remains arduous.

(5) During the transitional period of power grid development, the security contradiction is prominent. The construction of power market must be based on the safe and stable operation of power grid.

\section{Design of power spot market mode}

In order to promote the pilot projects well, it is necessary to design the key elements of the power spot market trading mechanism (rules), mainly including the bidding mode, clearing mode, pricing and congestion processing mechanism, unit commitment mode, coordination of power market and auxiliary services, etc.

\footnotetext{
" Corresponding author: fanmenghua@sgeri.sgcc.com.cn
} 




Fig. 1. Key elements of power spot market.

\subsection{Bidding mode}

Generally speaking, there are two bidding methods in the power market: unilateral bidding on the generation side and bilateral bidding on the generation side and load side. As shown in Table 1, from the international experience, the bilateral bidding of power generation and load is often used in the day-ahead market. While unilateral bidding on the generation side is often used for real-time market, since it is close to the real-time operation. The characteristics of the two bidding modes are compared as shown in Table 2.

Table 1. Typical bidding modes in power markets.

\begin{tabular}{|c|c|}
\hline $\begin{array}{c}\text { Typical } \\
\text { Power Market }\end{array}$ & Description \\
\hline $\begin{array}{c}\text { PJM Power } \\
\text { Market }\end{array}$ & $\begin{array}{c}\text { Bilateral bidding in Day-ahead market. } \\
\text { Unilateral bidding on the generation side } \\
\text { for real-time market, with ultra-short-term } \\
\text { load forecasting results of PJM. }\end{array}$ \\
\hline $\begin{array}{c}\text { Australian } \\
\text { Power Market }\end{array}$ & $\begin{array}{c}\text { Power Pool with unilateral bidding on the } \\
\text { generation side. Market clearing based on } \\
\text { load forecasting and auxiliary service } \\
\text { demand provided by the market operator } \\
\text { (AEMO) }\end{array}$ \\
\hline $\begin{array}{c}\text { UK Power } \\
\text { Market }\end{array}$ & $\begin{array}{c}\text { Bilateral bidding in Day-ahead market. } \\
\text { For real-time balancing, balancing } \\
\text { adjustment bidding is needed for market } \\
\text { participants in the balancing mechanism. }\end{array}$ \\
\hline
\end{tabular}

Table 2. Comparison of two bidding modes in power markets.

\begin{tabular}{|c|l|l|}
\hline Modes & \multicolumn{1}{|c|}{ Advantages } & \multicolumn{1}{c|}{ Disadvantages } \\
\hline Unilateral & $\begin{array}{l}\text { Generally the bidding } \\
\text { and procurement is } \\
\text { organized by the } \\
\text { market operator as } \\
\text { agent for demand side, } \\
\text { thus the scope and } \\
\text { intensity of } \\
\text { competition are } \\
\text { controllable. }\end{array}$ & $\begin{array}{l}\text { (1) Lower market } \\
\text { efficiency due to lack } \\
\text { of participation of } \\
\text { demand side. } \\
\text { (2) High demand for } \\
\text { competition in the } \\
\text { market structure of } \\
\text { power generation side }\end{array}$ \\
\hline $\begin{array}{c}\text { Bilateral } \\
\text { bidding }\end{array}$ & $\begin{array}{l}\text { The market efficiency } \\
\text { is higher and the price }\end{array}$ & $\begin{array}{l}\text { The market design is } \\
\text { more complex, which }\end{array}$ \\
\hline
\end{tabular}

\begin{tabular}{|l|l|l|}
\hline $\begin{array}{l}\text { is not easy to be } \\
\text { distorted. }\end{array}$ & $\begin{array}{l}\text { has higher } \\
\text { requirements for the } \\
\text { maturity and credit of } \\
\text { the market } \\
\text { participants. }\end{array}$ \\
\hline
\end{tabular}

The market concentration of power generation side in some regions of China is relatively high. With the opening of user's option and the cultivation of power suppliers, it is suggested that bilateral bidding can be applied for day-ahead market to avoid market manipulation and improve market efficiency. For the real-time market, in order to ensure the safe operation of the system, unilateral bidding can be adopted according to the results of ultra short term load forecasting.

\subsection{Settlement mode}

Currently, there are mainly two ways: System Marginal Price (SMP) and Pay as Bid (PAB) [3-5]. The characteristics of the two clearing methods are compared as shown in Table 3.

SMP refers to the increased power purchase cost of the system to meet the load demand by the most economical means when a unit load is added to the system under certain constraints. Under the system marginal price settlement mechanism, all transactions are settled according to the system marginal price.

PAB is to distribute the generation load from low to high according to the bidding of generator (or unit) under certain constraints, and settle the transaction according to the actual bidding until the system load balance is met. Generally, it is used in combination with the output adjustment bidding mode based on the physical contract decomposition curve. For example, the real-time balance market in UK adopts the PAB pricing method.

Table 3. Comparison of two settlement modes in power markets.

\begin{tabular}{|l|l|l|}
\hline Modes & \multicolumn{1}{|c|}{ Advantages } & \multicolumn{1}{c|}{ Disadvantages } \\
\hline \multirow{5}{*}{ SMP } & $\begin{array}{l}\text { (1) It can provide } \\
\text { effective market } \\
\text { economy signal. } \\
\text { (2) It has incentive for } \\
\text { generators to offer } \\
\text { lower bidding prices } \\
\text { and thus can save the } \\
\text { power purchase costs. It } \\
\text { is also beneficial for the } \\
\text { equal competition } \\
\text { between small and large } \\
\text { generation companies. } \\
\text { (3) It has incentive for } \\
\text { the generation capacity } \\
\text { or exercising the market } \\
\text { power. } \\
\text { (2)Both high bidding } \\
\text { price deviating from the } \\
\text { cost and the negative } \\
\text { profit of the unit (the } \\
\text { market clearing price is } \\
\text { production efficiency } \\
\text { and reduce costs. }\end{array}$ & $\begin{array}{l}\text { lower than the unit } \\
\text { generation cost) might } \\
\text { happen. }\end{array}$ \\
\hline \multirow{5}{*}{ PAB } & $\begin{array}{l}\text { (1) Under the same } \\
\text { generation bidding } \\
\text { strategy, compared with } \\
\text { SMP, it can save the } \\
\text { total cost of system } \\
\text { power purchase. } \\
\text { (2) It can prevent the }\end{array}$ & $\begin{array}{l}\text { (1) Market entities may } \\
\text { not bid according to } \\
\text { marginal cost / benefit. } \\
\text { (2) Power producers } \\
\text { tend to raise the bidding } \\
\text { price, which may make } \\
\text { the overall level of PAB }\end{array}$ \\
\hline
\end{tabular}




\begin{tabular}{|l|l|l|}
\hline $\begin{array}{l}\text { generation companies } \\
\text { from manipulating the } \\
\text { market price by using } \\
\text { the measures of retained } \\
\text { capacity. }\end{array}$ & $\begin{array}{l}\text { higher than that of } \\
\text { SMP. } \\
\text { (3)It is not beneficial } \\
\text { for equal competition } \\
\text { among different power } \\
\text { producers. }\end{array}$ \\
\hline
\end{tabular}

At present, China's power supply exceeds demand, and plans coexist with the market. In some areas, there is a tendency of vicious competition and bidding price reduction on the power generation side, so PAB can be used to guide power producers to make rational biddings. With the gradual development of the market, SMP can be gradually used to provide more effective market competition signals. In some regions, the use of mixed settlement method can also be explored, that is, based on a certain price level, the winning generators whose bidding prices are below this level will be settled by SMP mechanism, while the winning generators whose bidding prices are above this level will be settled by PAB mechanism.

\subsection{Pricing mode}

There are two typical pricing methods in power market: locational marginal price (LMP) and zonal price.

LMP refers to the lowest cost of power supply for the new unit load of the node, when considering the physical characteristics of the network, i.e. transmission congestion, network loss and marginal cost of each generating unit. LMP includes three parts: electric energy, network loss and congestion. LMP is widely applied in the US power market

Zonal price refers to dividing the power grid into some fixed zones in advance according to the network congestion, and calculating the zonal marginal price according to the unit and load bidding in the zone to reflect the power supply and demand relationship in the zone. The European market mainly adopts zonal price mechanism.

Table 4. Comparison of two pricing modes in power markets.

\begin{tabular}{|c|l|l|}
\hline Modes & \multicolumn{1}{|c|}{ Advantages } & \multicolumn{1}{c|}{ Disadvantages } \\
\hline \multirow{5}{*}{ LMP } & $\begin{array}{l}\text { The combination of the } \\
\text { economic and physical } \\
\text { properties of the power } \\
\text { commodity can guide } \\
\text { the power generators } \\
\text { and users to use the } \\
\text { power grid reasonably, } \\
\text { and provide the } \\
\text { economic signal for } \\
\text { effective investment of } \\
\text { power transmission. }\end{array}$ & $\begin{array}{l}\text { is complex with } \\
\text { relatively less } \\
\text { calculation } \\
\text { transparency. } \\
\text { (2) The price changes } \\
\text { frequently with time } \\
\text { and space, which } \\
\text { hinders the function of } \\
\text { price signal to some } \\
\text { extent. }\end{array}$ \\
\hline Zonal \\
Price \\
$\begin{array}{l}\text { Relatively more } \\
\text { concise, transparent } \\
\text { and predictable, and } \\
\text { easy for market } \\
\text { participants to } \\
\text { understand. }\end{array}$ & $\begin{array}{l}\text { (1) Reasonable division } \\
\text { of price zones has } \\
\text { some difficulties. } \\
\text { (2) Due to ignoring } \\
\text { the internal } \\
\text { congestions, the price } \\
\text { signal is distorted to } \\
\text { some extent. }\end{array}$ \\
\hline
\end{tabular}

Each province can choose the pricing mode according to the situation of power grid congestion and local market conditions. Considering the initial stage of the market and the provincial transmission tarriff system in China, zonal pricing or system marginal pricing(SMP) can be applied in the near future.

\subsection{Congestion management}

Different pricing modes correspond to different congestion management methods.

Congestion management with LMP [6]: Financial transmission right (FTR) is a kind of financial instrument specially corresponding to LMP pricing method. FTR defines the power to obtain congestion revenue between any two nodes, and the holder of FTR can obtain the revenue from price differences. The costs that the market operator uses to pay the FTR holders come from the congestion surplus generated by network congestion.

Congestion management with zonal pricing [7]: Due to the different prices among congestion areas, the market has congestion surplus. It is necessary to establish corresponding mechanisms to distribute this part of surplus. Based on European experience, the cross-border transmission capacity can be allocated by explicit or implicit auction, and the congestion surplus can be allocated to grid companies for grid construction in congested areas.

\subsection{Unit commitment}

There are two main ways of unit commitment: centralized scheduling optimization and self-schedule of market participants.

Centralized scheduling optimization: Taking PJM in US as an example, the unit commitment considering safety constraints (SCUC) is carried out seven days in advance, and then the rolling optimization adjustment is carried out according to the clearing results of the day ahead market. In the day ahead market, clearing calculation is carried out according to the information such as start-up and shut-down cost, no-load cost and generation bidding curve declared by the unit. After the market clearing, PJM will, according to the load forecast of the next day, do rolling optimization and determine the unit commitment of the next day. Then the power generation enterprises will be notified which need to add the unit.

Self-schedule of market participants: taking UK as an example, because the daily power generation and consumption curves are determined by market participants, the dispatching centre does not make centralized arrangement for unit commitment, but discloses system balance information to market participants to guide them adjusting transaction plans or maintenance arrangements.

In China, the proportion of conventional coal-fired units is large, while that of gas-fired units is small. The coal-fired unit has the characteristics of long start-up and shut-down period and extra cost. In order to ensure the balance of power supply and demand, optimize the 
utilization efficiency of power generation resources and promote the consumption of clean energy, the unit commitment needs to be optimized in a central way by the dispatching centre. The spot market provides a kind of market-oriented means for dispatching to arrange the unit commitment plan. It is suggested that the market will gradually determine the unit commitment mode in the future.

\subsection{Coordination of energy and auxiliary service market}

The connection between auxiliary service market and power market mainly includes independent trading mode and co-optimization mode [8].

Independent trading mode: Each power commodity market is regarded as an independent competitive market and is cleared separately according to the biddings and demand.

Co-optimization mode: The auxiliary service markets and energy markets shall be optimized in a unified way, with the objective of the lowest comprehensive purchase cost of each market. This not only minimizes the purchase cost, but also adds constraints to the optimization process. This is the approach adopted by most markets in the United States.

In the early stage of China's electric power market, the planned power supply still accounts for a certain proportion, and the active auxiliary service market and the electric energy market can be traded independently. With the gradual development and maturity of the market, we can explore the co-optimization mode of auxiliary services and power market to further promote the overall operation optimization of the system.

\section{Key issues and suggestions}

\subsection{Market power mitigation}

The market concentration of power generation side in China is relatively high, and there is a trend of further increase with the restructuring of state-owned enterprises. To solve the market power problem, we need to take multiple measures simultaneously and comprehensively. Firstly, expand the market scope and reduce the market share of individual enterprises by the construction of national electricity market. Secondly, improve market rules and introduce mechanisms such as price ceiling and emergency intervention. Thirdly, improve market regulation by strictly monitoring the market power abuse and collusion behaviour, increasing penalties for violations, and enhancing the supervision of information disclosure.

\subsection{Cross subsidies resolution}

China has implemented policy based cross subsidies for residential and agricultural customers for a long time, with low power tariff level for residential and agricultural customers. With the development of electricity market reform and China's economic and social development, it has become an urgent problem to properly deal with the cross subsidy of electricity price. At present, it is still difficult to completely cancel cross subsidy. We can resolve the contradiction step by step. On the one hand, it is necessary to make clear the cross subsidy responsibilities for all kinds of users, and list the standards of cross subsidy clearly in power tariff. On the other hand, it is important to establish a market-oriented electricity price formation mechanism and promote the industrial and commercial power consumption to participate in the electricity market comprehensively.

\subsection{Coordination of regulated and market based mechanism}

According to existing policies, the deregulated power quantity accounts for about $65 \%$ on the consumption side, and about $45 \%$ on power generation side. The imbalance of deregulation on generation and consumption side will affect the construction of power market. It is suggested that the regulated power generation should match the consumption side, with part of the regulated power generation using market based price instead of government regulated price. Besides, reasonable allocation should be carried out for the unbalanced funds in the power market which is generated by the imbalance of plan and the market

\section{Acknowledgement}

This paper was supported by Science and Technology Project of State Grid Corporation of China (Research on Mode Selection and Evolution Path of Power Spot Market on the Basis of National Unified Power Market).

\section{References}

1. S.J. Liu, J. Yang, Eur. Phys. J. Elec. Powe. 50, 1 (2017)

2. H.Y. Guo, Q.X. Chen, H.W. Zhong, Y. Wang, W.J. Zhang, Q. Xia, J. Auto. of Elec. Powe. Syst. 41, 1 (2017)

3. Y.L. Wang, L.Z. Zhang, Y.H. Yang, J. Powe. Syst. Tech. 28, 14(2004)

4. J.X. Wang, H.W. Zhong, Q. Xia, Y. Wang, X.W. Lai, X.Z. Guo, J. Auto. of Elec. Powe. Syst. 43, 7 (2019)

5. Y.H. He, M. Zhou, Z.Y. Wu, S. Y. Long, J. Xu, J. Powe. Syst. Tech. 42, 3520(2018)

6. C.H. Li, S.H. Du, J. Su, D.Q. Wang, J. Mode. Elec. Powe. 24, 82 (2007)

7. Z. Li, B. Pang, G.D. Li, M.H. Fan, H.Y. Qu, J. Auto. of Elec. Powe. Syst. 41, 2 (2017)

8. J.Z. Zhu, Y. Yu, P.P. Xie, Z.X. Jing, J. Zou, P. Z. Xuan, J. Sout. Powe. Syst. Tech. 13, 37 (2019) 